\title{
الشاهد الصندوع في شروح الجمل للزجّاجيّ
}

الباحثة فاطمة سـمير مجيد/ كليّة التربية/ جـامعة واسـ

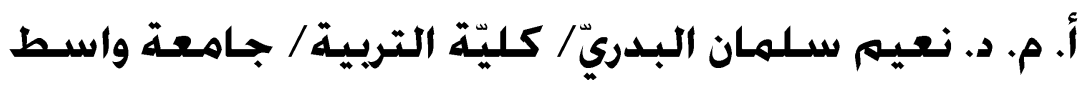

الحمد له ربّ العالمين والصلاة والسلام على خاتم الأنبياء و المرسلين نبينا محمّد (صلى الله عليه وسلّم)

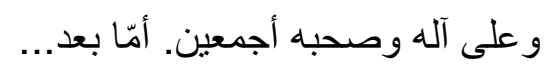

فِإنّ ظـاهرة الانتحسال شغلت مكانـة كبيرة في النحو العربيّ، إذّ كُُرت الثـواهد المصنوعة والمجهولة القائل في الكتب النحويّة، و الثو اهد المصنو عة هي التي يضعها صاحبها ويقول إنّه مدّا قالته العرب و أصبحت هذه الثوا هد تشكّل ظاهرة خطيرة في الثعر العربيّ حتّى تخلّل ذلك الثـواهد النحويّة وليس النحويّة فحسب بـل

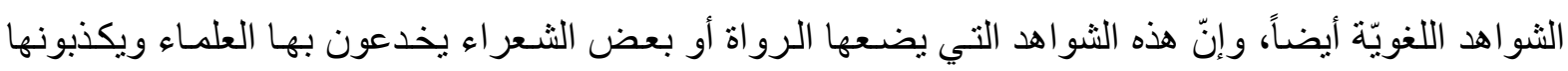
عليهم ويقولون إنّ هذا ممّا قالته العرب وقد قيل إنّ هذه الثوا هد لا يتجاوز عددها الخمسين شـاهداً وسـأتكلّم عن هذا الموضوع في هذا البحث إنْ شـاء الله تعالى.

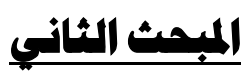 \\ الثناهد المَصنوع \\ الثاهد المصنوع لدى شرّاح الجمل

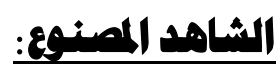

يقول الدكتور عبد الجبار النايلة: "الثـواهد التي يضـعها صـاحبها وينشدها على أنّها ممّا قالته العرب الفصحاء"(') وقد شـلت ظـاهرة الانتحال مكانـة كبيرة في الثـعر العربيّ، إذ كثُرت مرويّات الثـعر المجهولة القائل أو ممّا قاله شاعر وينثده ويقول إنّه ممّا قالته العرب،وقد أثنار إلى هذا أيضـاً هو سييويه، إذ قـال: "و اعلم

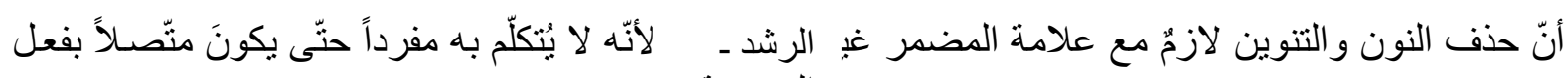

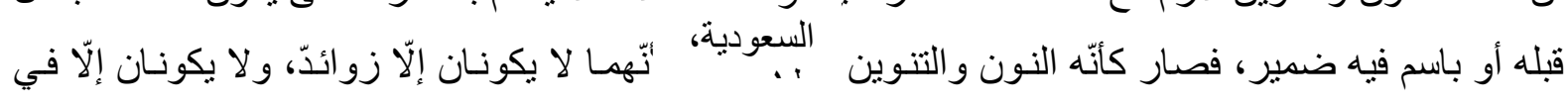
أواخر الحروف. و المظهرُ و إن كان يعاقِب النون والتنوين فإنّه ليس كعلامة المضمر المتّصل؛ لأنّه اسم ينفصل ويُيتََأ، وليس كعلامة الإضمار لأنّها في اللفظ كالنون والتنوين، فهي أقرب إليها من المظهر، اجتمع فيها هذا و المعاقبة. و وقد جاء في الثعر ، وزعموا أنّه مصنوع: هُمُ القائلونَ الخيرَ و الآمرونهه إذا ما خشو ا من مُحْدِثِ الأمرِ مُعْظما"(؟).

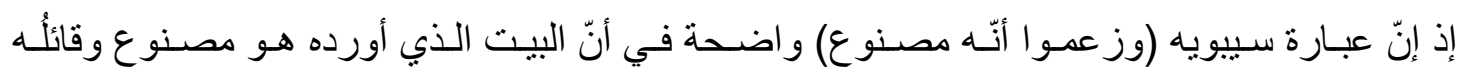
مجهول، و عند الرجوع لأكثر من مصدر نجدُ هذا الكلام نفسه في أغلب المصسادر النحويّة وأيضـاً الأبيـات الثعريّة المذكورة نفسها في كتاب سيبويه.

ويقول ابن سلّام (ت (ابr هـ) : "وفي الثـعر مصنوعٌ مفتعلٌ موضوع كثير لا خيرَ فيه، و لا حجّة في

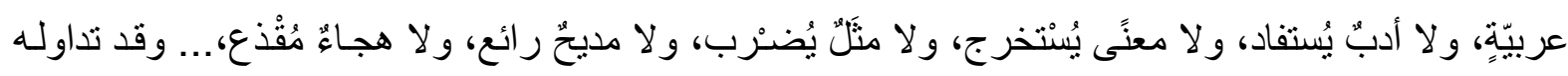


قومٌ من كتابٍ إلى كتابٍ، لم يأخذوه عن أهل الباديـة، ولم يعرضوه على العلمـاء"(")، وقال أيضـاً: "وللشـعر

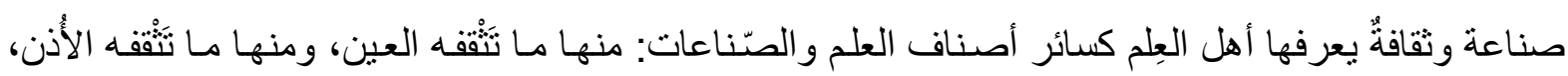

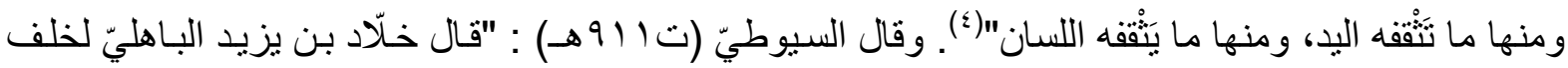

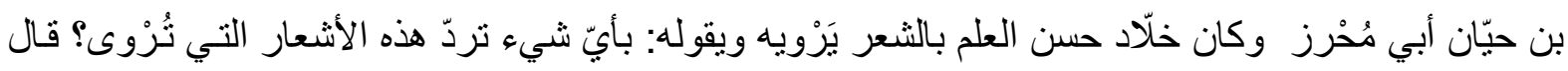

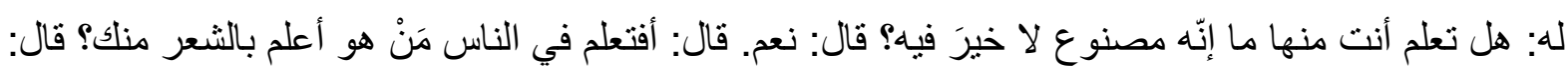

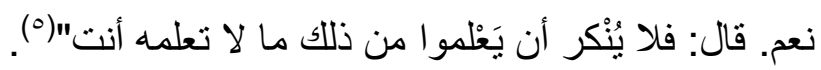

وقد تحدّث العلمـاء عن الثـعر المصنوع و الموضـوع و الذي أصبح يُشَّل ظـاهرة خطيرة في الثـعر

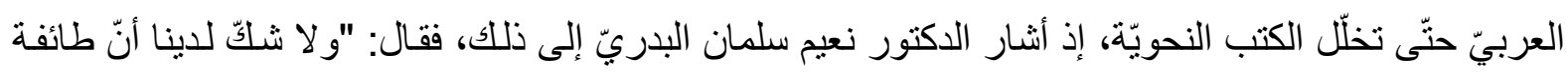

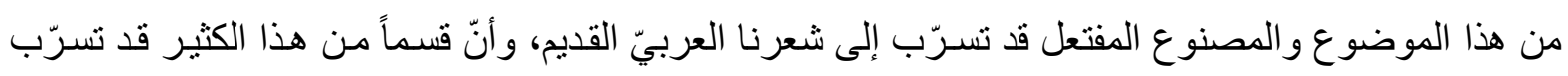

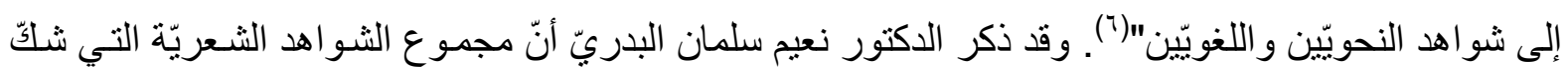
العلماء فيها وقيل أنّها مصنو عة لا تتجاوز الخمسين شاهداً وأنّ صُنّاعها مجهولون في الغالب إلّا أنّهم في بعض

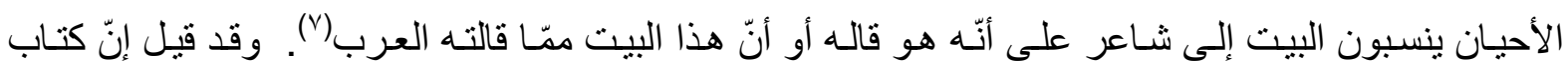
سيبويه قد خرج إلى الناس و هذّبه سيبويه ونظر فيه ودثّقه وضبّطه في شو اهده الثـعريّة فكيف يمكن أن تتو اجد فيه شواهد مصنو عة وإنّ ما قيل من ورود أبيات شعريّة مصنو عة في كتاب سيبويه إنّما هو من بـاب الطعن في

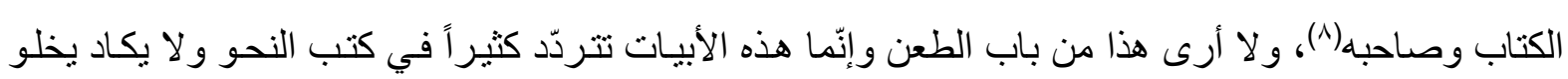

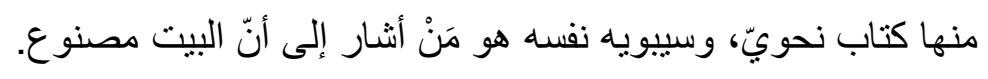

وقد قال الدكتور نعيم سلمان البدريّ: "و على الرّ غم ممّا تقدّم أرى أنتّا لا نستطيع أن نتّهم علمـاء العربيّة أنّهم كانوا يضعون الثوا هد أو يكذبون فيما يروونه منها؛ ذلك أنّ النصوص التي بين أيدينا تشير إلى أنّ بعض أنس الرواة وبعض الثعر اء كانوا يصنعون الثوا هد ويخدعون بها العلماء أو يكذبونها عليهز" (9).

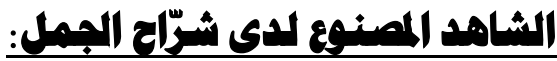

لقد وردت الثـو اهد المصنو عة في كتب النحويّين و اللغويّين كمـا ذكرتُ سـابقاً، وكمـا أحصـاها أيضـاً

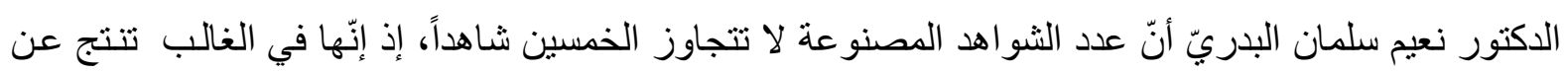
قيام شاعر بعمل بيت ويقول هذا ممّا قالته العرب أو ينسبه لشـاعرٍ آخر ، وأمّا الزجّاجيّ صـاحب كتاب الجمل،

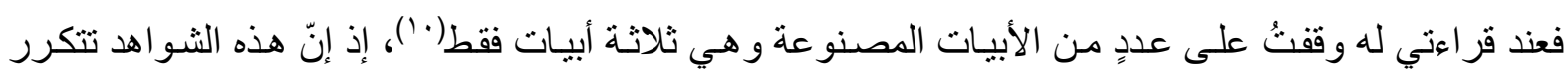
دائماً في كتب النحو، وفي أيّ كتاب نحويّ أو لغويّ تذكر هذه الثوا اهد ويُقـال عنها أنّها مصنو عة لوجود دهي دلائل

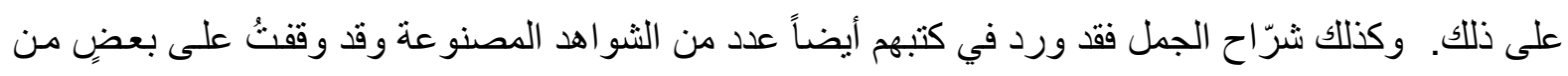

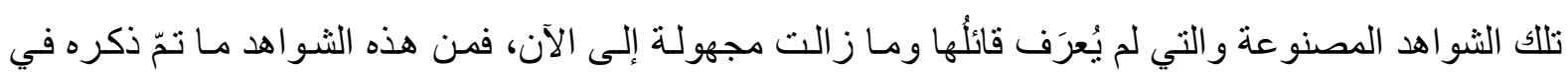
أغلب شروح الجمل، وهو (''):

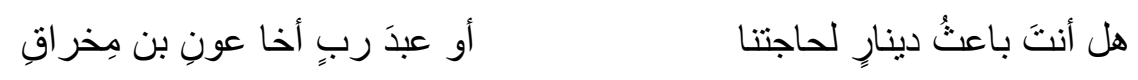

وقد ذكره شرّاح الجمل و هو من الثو اهد المصنو عة لكنّهم لم يصـرّحو ا بذلك و إنّمـا ذكر محقّقو الثـرّاح

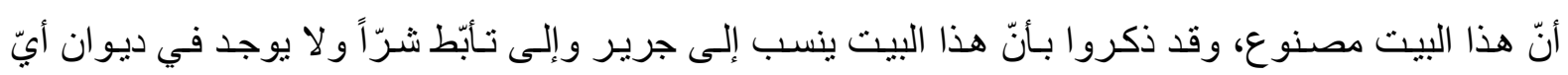




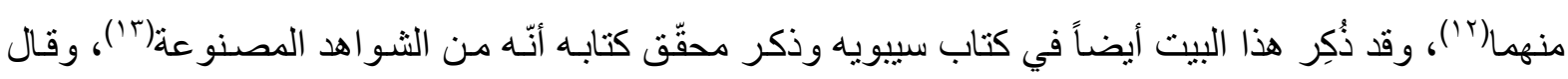
سيبويه: "وزعم عيسى أنّم ينشدون هذا البيت:

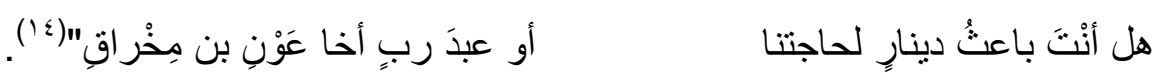

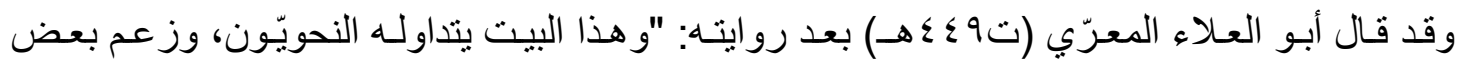

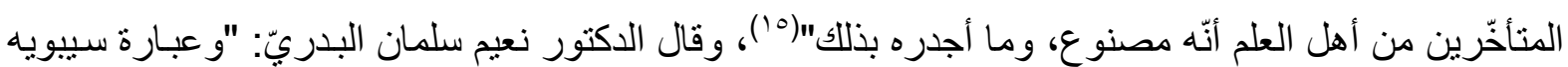

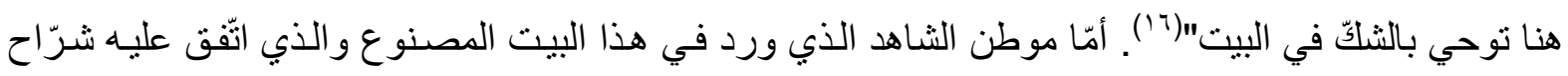

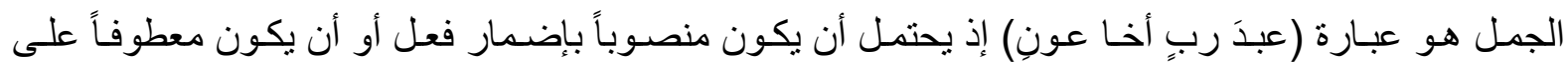

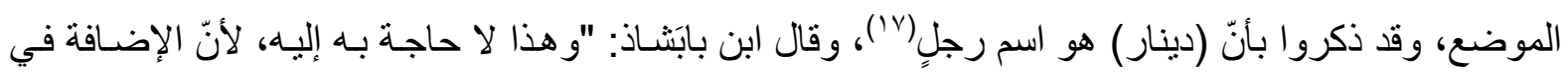

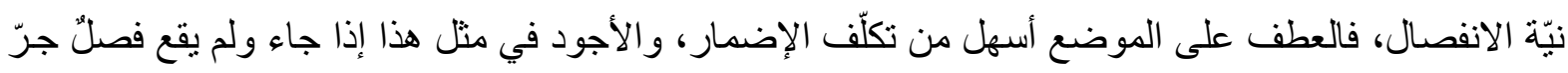

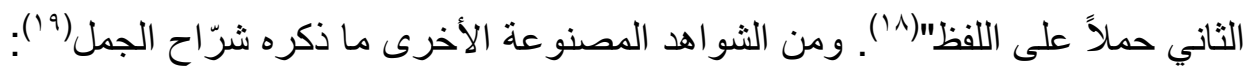

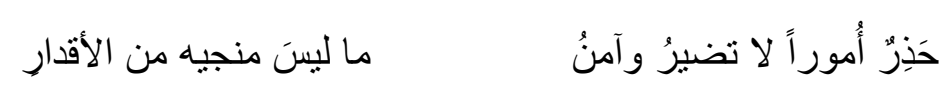

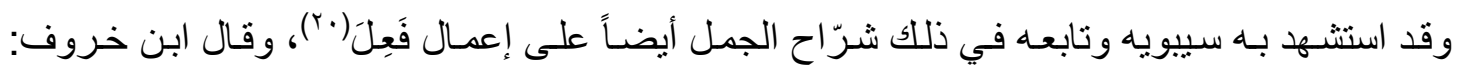

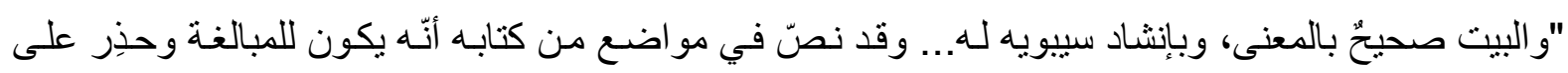
وزن (فخذ)، و الحذر: الخائف وهو خبر ابتداءٍ مضمر. لا تضير، يقال: ضـارّه يضيره، وضرّه يضرّه بمعنى و

$$
\text { (آمن) اسم فاعل عامل في (ما)..."(rان). }
$$

وقد نُسِبَ هذا البيت إلى أبـان اللاحقيّ، قـال النّحساس (تمبrهـ) في كتابـه عن هذا الثـاهد: "حدّثني عليّ ين سليمان قال حدّثنا محمّد بن يزيد قال: سمعتُ أبا عثمان المـازنيّ يقول: قـال أبو عثمان اللاحقيّ: لَقِيني

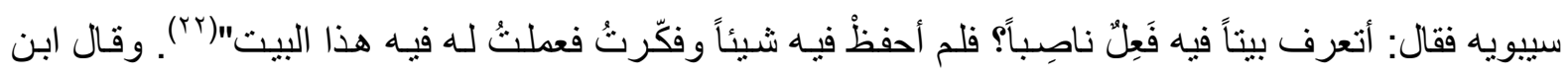
خروف: "وفي هذا الخبر إقرارُ اللاحقيّ على نفسه بالكذب فلا يُصدّق في الثانية"(r")، وقد ذكر العلويّ في كتابه

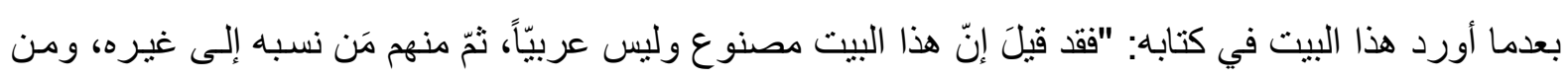
ها هنا ردّ على سيبويه الاحتجاج به، وقد جاء في شعر زيد الخيل إعماله ممّا لا يطعن فيه قال:

$$
\text { أناني أنّهم مزِقون عرضي }
$$

وقد قال البغداديّ (تب و • ( هـ): "على أنّ سيبويه استدلّ على عمل فَعِل بهذا البيت، ومنعـه غيره وقـال:

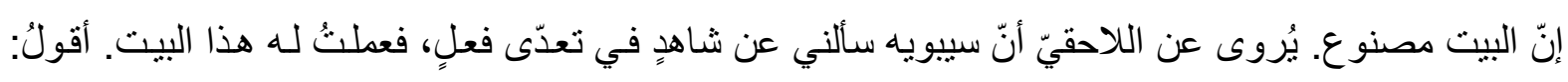
إنْ طُعِنَ على سيبويه بهذا البيت فقد استشهدَ ببيتٍ آخر لا مطعن عليه فيه، وهو قول لبيد الصاحبيّ:

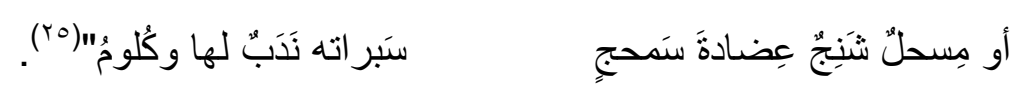

أمّا البيت الثاني وهو البيت المصنوع فقد قـال البغداديّ : "و إذا حكى أبو يحيى مثنل هذا عن نفسـه

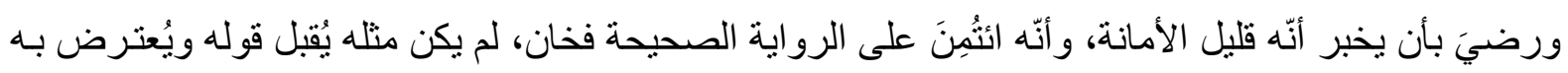

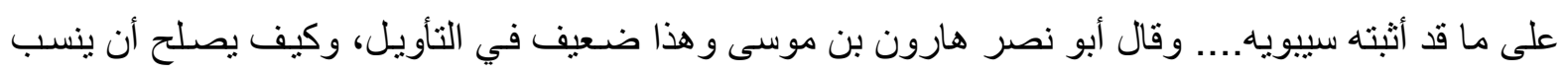


اللاحقيّ إلى نفسه ما يضعُ منه ولا يجِلّ أو كيف يجوز هذا على سيبويهـ... و إنّما أراد اللاحقيّ بقوله: (فوضعتُ له هذا البيت): فرويتُه"(بr).

وأرى أنّ تأويل البغداديّ لقول اللاحقيّ (فوضعتُ له هذا البيت) بمعنى: رويته، بعيد؛ إذ المعنى واضـح

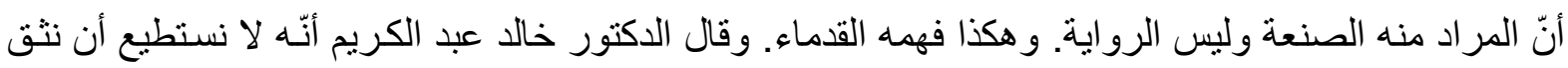

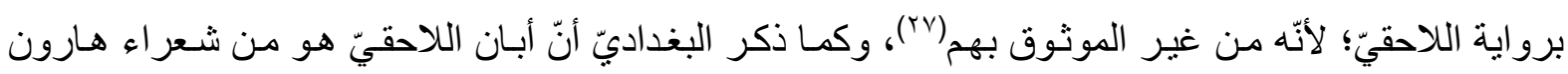

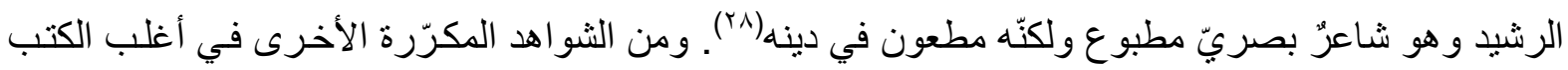
النحويّة وقد وردت في شروح الجمل وهي من الشواهد المصنوعة أيضاً هو (ج)ج):

إذا ما خَشَوا من مُحْدِث الأمر مُعْظما هُمُ القائلونَ الخَيْرَ والآمِرونهُ

فهذا البيت من الأبيات المجهولة القائل التي أنشدها سيبويه، وقد قال محقّق كتاب البسبط في شرح

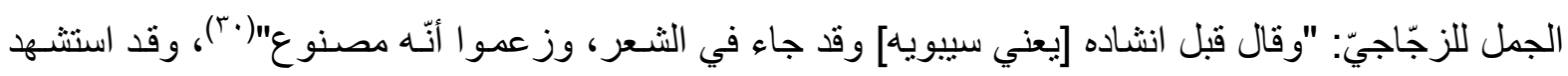
بهه سيبويه وتابعه شرّاح الجمل في ذلك وجعلوه شـاهداً على أنّ حذف النون و التنـوين لازمٌ مـع علامـة المضمر

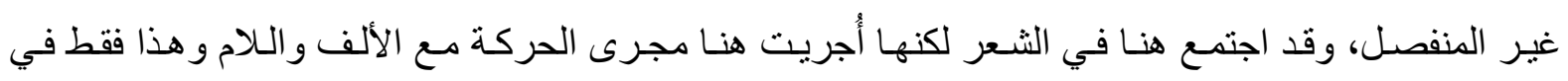
الثعر (الr)، ولم يكتفِ سيبويه بهذا و إنّما أنشــ شـاهداً آخر و هو أيضـاً من الثـواهد المصنو عة وموطن شـاهده كالثاهد السابق وقد تابعه ابن عصفور في ذلك وأورده في شرحه وهو (r؟r):

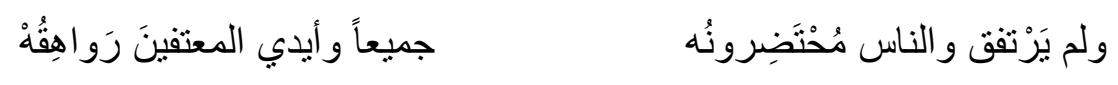

قال النّحاس (تمبسهـ): "أمّا البيتان اللذان أنثدهما سيبويه وشرِكه الفرّاء في أحدهما فلا يُعرف مَنْ

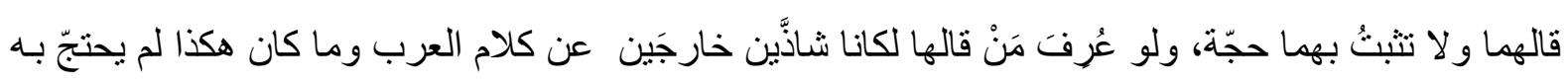
في كتاب الله جلّ و عزّ، و لا يدخل في الفصيح"(r"r)، وقال البغداديّ عن البيتين: "وقد روى سيبويه محمولَين

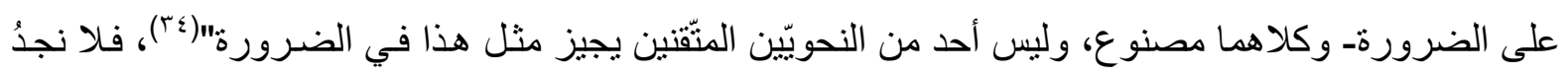

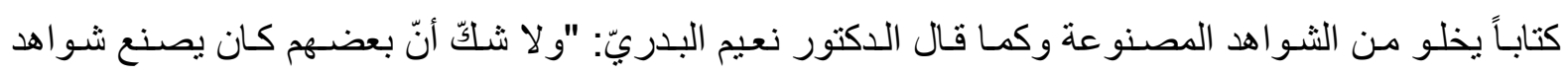

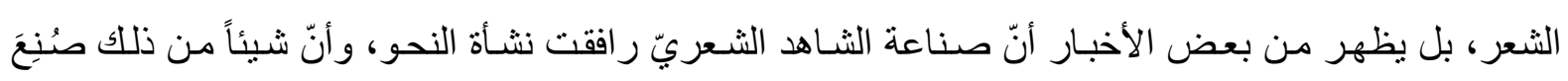

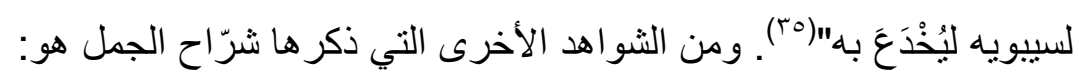

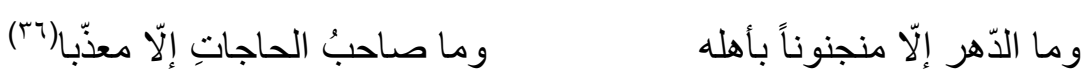

وقد جعلو ا هذا البيت شاهداً على نصب (منجنونـاً) على خبر (مـا)(־َ)، وهو أنّه إذا دخلت على (مـا) (إلّا) بطُل النصب لزوال المشابهة، أمّا هذا البيت ففيه وجهان إمّا أن يكون أوقع الاسم موقع المصدر ، وأجراه

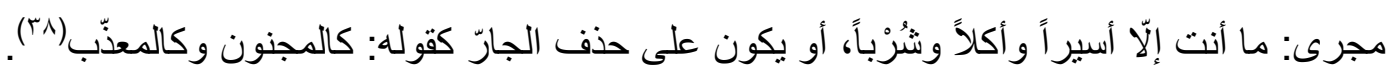
و هذا البيت لم ينسبوه إلى قائل معيّن، وقد ذكر الدكتور نعيم البدريّ كلامـاً بخصوص هذا البيت أنّ ابن مالك مَن صنعه لقوله: "قال ابن مالك: ورُوِيَ عن يونس من غير طريق سيبويه إعمال (مـا) في الخبر

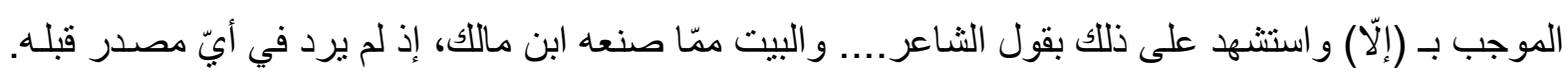

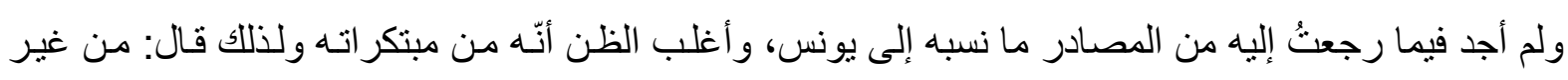


طريق سيبويه"("9). وقد أورد ابن عصفور بيتاً في شرحه للجمل وهو من الأبيات التي صنعها ابن مالك، إذ قال

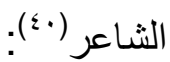

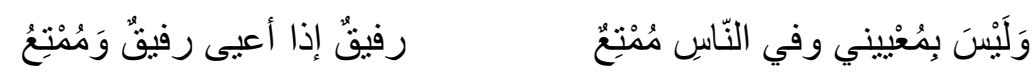
أورده شـاهداً على إلحساق نون الوقايـة لاسم الفاعل رغم اتّصـاله بالضمير ، والبيت غير منسوب و لا يوجد له ذكرٌ قبل ابن مالك( ()،ويرى الدكتور نعيم سلمان البدريّ إنّ هذا البيت هو من صناعة ابن مالك إذ قال:

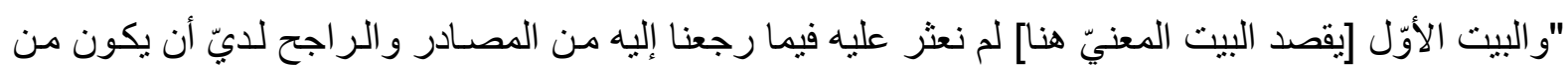

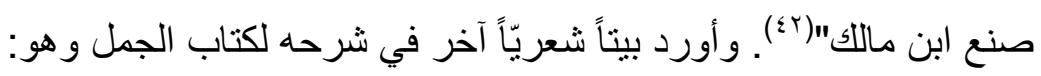

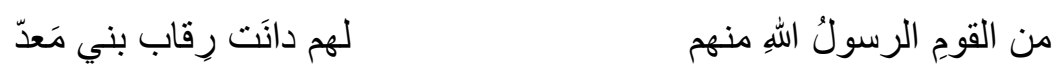

وقد ذكره ابن عصفور شاهداً على دخول (أل) التعريف بالجملة الاسميّة وقد ذكر هذا من الضرورات

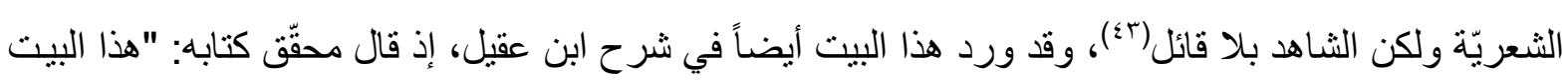

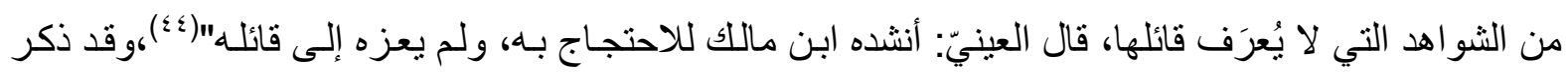

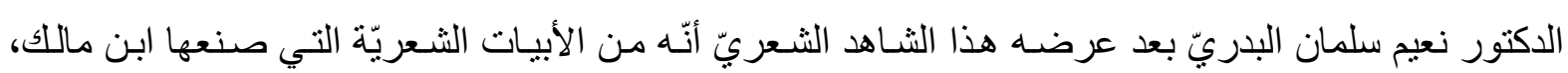

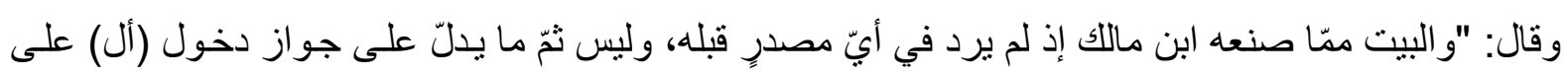

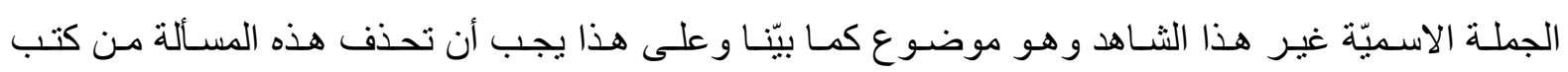
النحو"(0؛.) ومن هذين القولين يتبيّن لنـا أنّ ابن مالك هو الذي أنشده إذ لم يرد في أيّ مصدر قبله ولم يـرد منسوب إلى قائل معيّن، فالبيت من صناعة ابن مالك. وقد ورد شاهد آخر مصنوع على توكيد النكرة المحدودة،

\section{قد صَرّت البكرةُُ يوماً أجمعا}

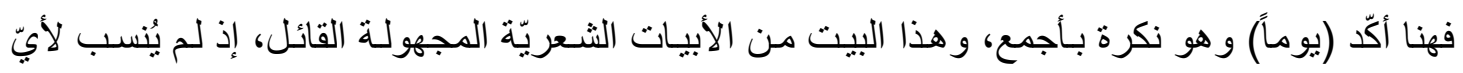

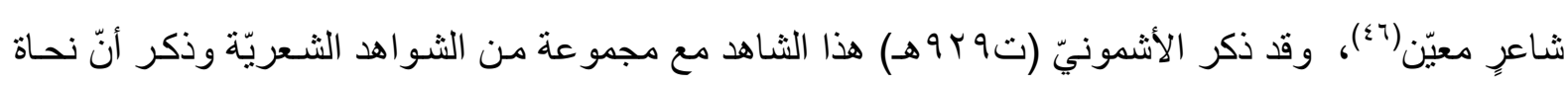

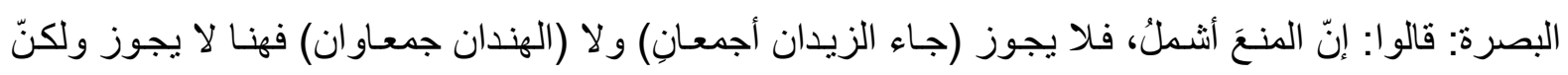

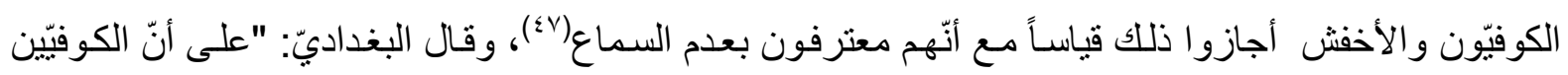

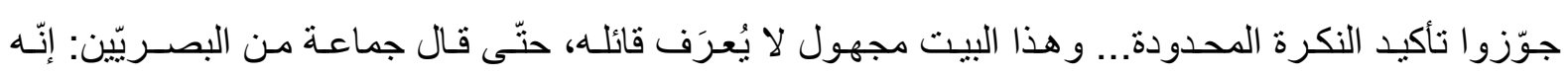
مصنوع"(^؛). فعلى رأيّ البصريّين هذا البيت مصنوع إذ لم ينسب لأيّ قائل، أمّا الكوفيّون أجازوا ذلك مـع أنّهم

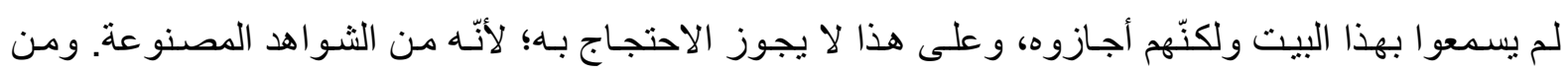

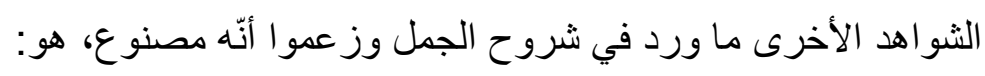

$$
\text { فـــا والَولا واحَ }
$$

وقد استشهدوا بهذا البيت الشعريّ على استعمال (والَ، واحَ، واسن) أفعالاً من لفظ المصـادر، فقد أخذها

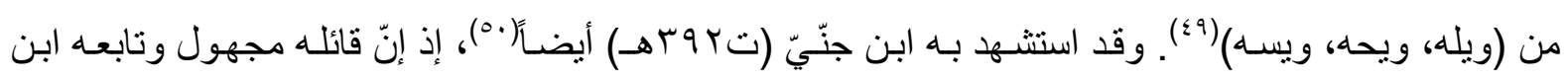

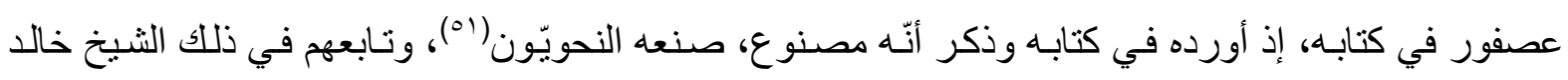


الأز هريّ (ته ـ وهـ) في كتابه إذ قال: "وذهب بعض البغداديّين إلى أنّ ويحه وويله وويسه منصوبة بأفعال من لفظها و أنشد:

$$
\text { فمـا وال ولاواح }
$$

قال المُر اديّ في شرح التسهيل وهو مصنوع "(Or).

فمن خلال هذا الأقو ال يتبيّن لنا إنّ هذا البيت مصنوع، إذ لا يوجد قائل له وقد ورد في أكثر من مصدر و اتِقق النحاة على أنّه مصنوع. ومن الثواهد الأخرى التي وردت في شروح الجمل هو:

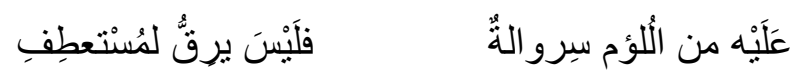

وقد جعلوه شاهداً على أنّ (سرو الةٌ) هي مفردة سر اويل وهذا مـا ذكره ابن بابَتـاذ وابن عصفور (ror.

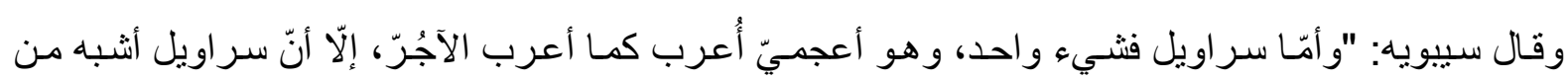

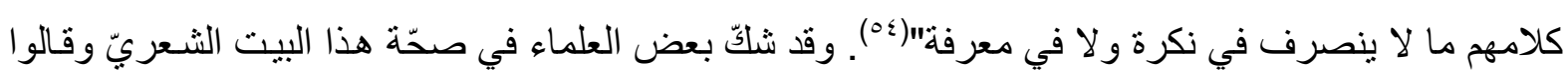

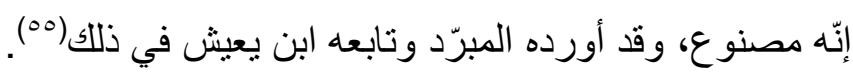

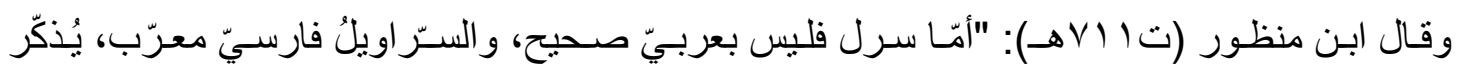

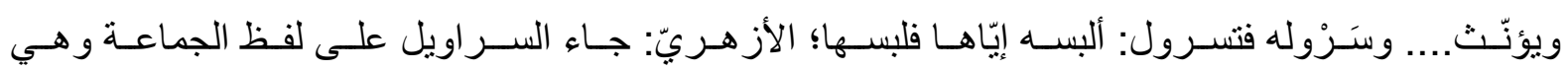

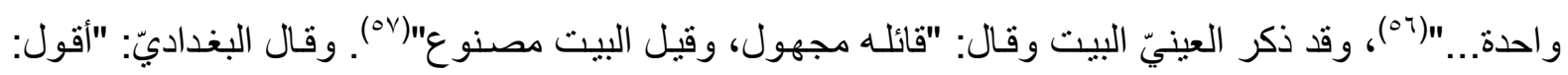
هذا البيت قيل مصنوع، وقيل قائله مجهول، والذي أثبته قال: إنّ سروالة واحدة السراويل، وكيف تكون سرو الة بمعنى قطعة خرقة، مع الحكم بأنّها واحدة السراويل، هذا لايكون، وقال السير افيّ: سروالة لغة في السراويل، إذ وند

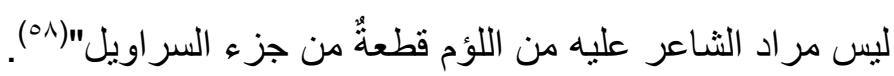
ويبدو لي أنّه من الثوا اهد المصنوعة كمـا ذهب إلى ذلك أكثر النحاة، وكمـا قـال الدكتور عبد الجبار النايلة إنّه ممّا ساعد على تسّرب مثل هذه الشو اهد المصنوعة أنّها مجهولة القائل، وقد استشهد بها النحويّون في وهي كتبهم مستتدين إلى ثقة منشدها فتخفى على العلماء صنعتها، فلهذا كان العلمـاء أكثر شكّاً في الثوا اهد المجهولـة بأنّها شو اهد مصنو عة(ه9). ومن الثوا اهد المصنو عة التي وردت في شرح الجمل لابن عصفور وقد ذكر و اضعهد وصانعه وهو خلف الأحمر، إذ إنّه مشهور في صنع الأبيات الثعريّة وكما ذكر الدكتور عبد الجبار النايلـة هذا

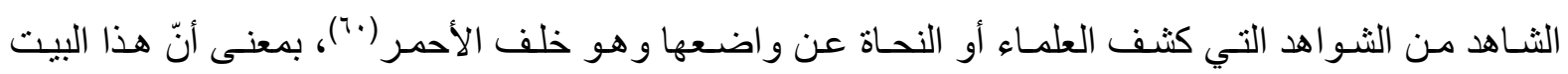
مصنوع، إذ قال:

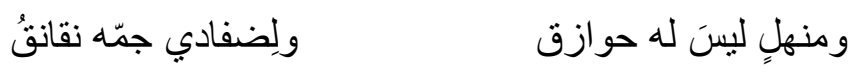

وقد استشهد به ابن عصفور على إبدال العين إلى ياء، فالأصل أن يقول ضفادع فأبدل العين و أصبحت

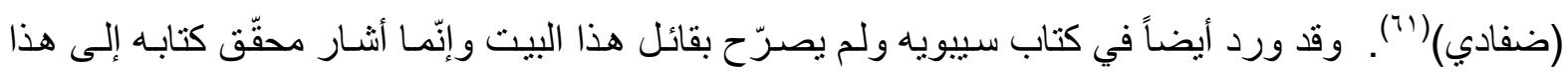

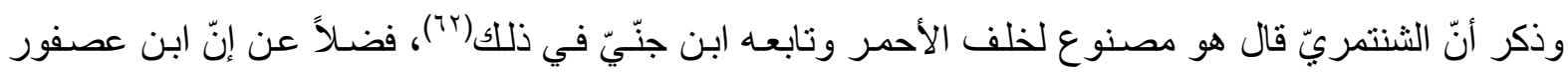

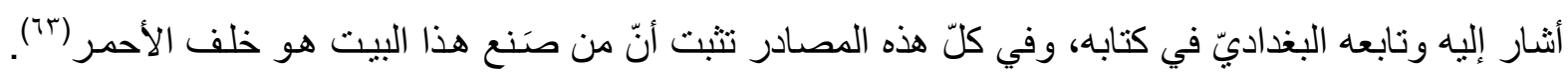


فهذا البيت في رأيّ بعض النحاة أنّه من الثو اهد المصنو عة ومن صنعه هو خلف الأحمر، وقد زخرت كتب النحو بمثل هذه الثو اهد و غير ها.

\section{الغاتمة:}

بعد الحديث عن الثواهد المصنوعة وعرض بعضاً من الثو اهد الثعريّة المصنوعة ووضع الأدلّة التي

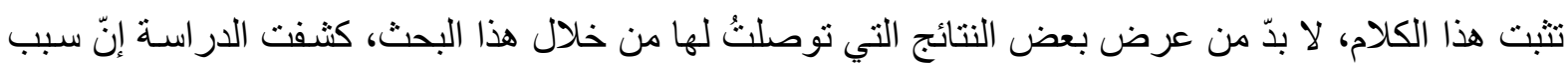

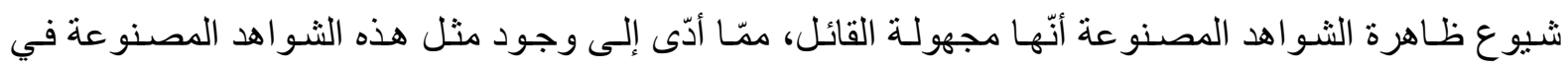

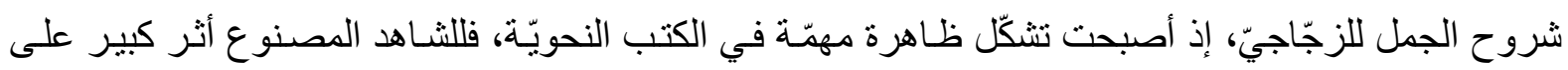
القاعدة النحويّة.

\section{المسادر والمراجع:}

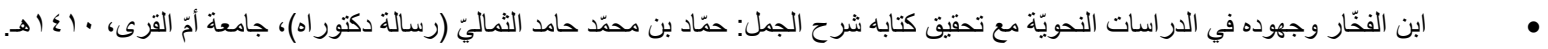

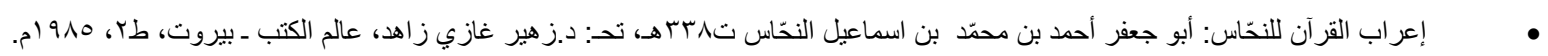

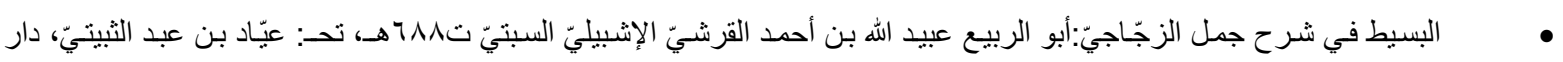

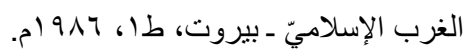

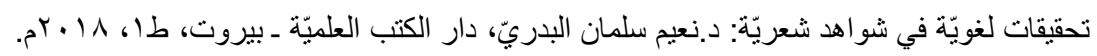

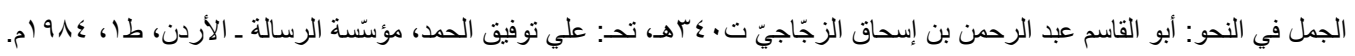

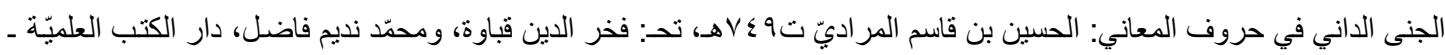

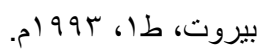

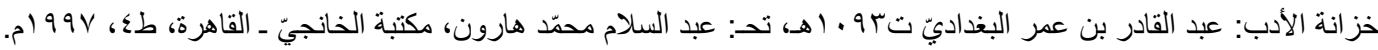

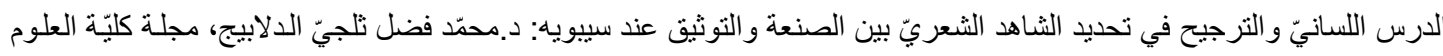

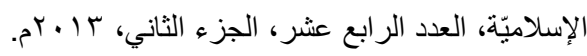
رسالة الغفران: أبو العلاء المعرّيّ تو ؟؟ هـ، تد: عائشة عبد الرحمن، دار المعارف، طو، (د.ت).

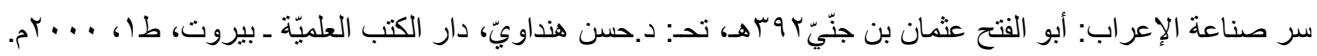

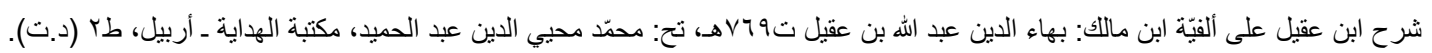

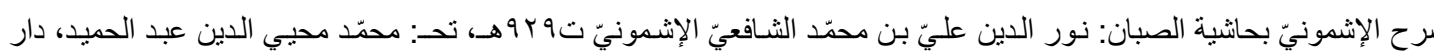
الكتاب العربيّ - بيروت، طا ،900 ام.

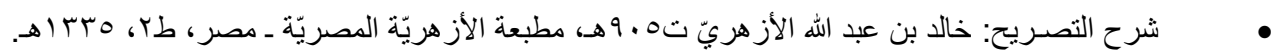

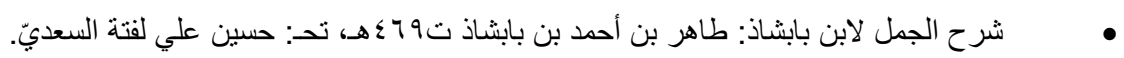

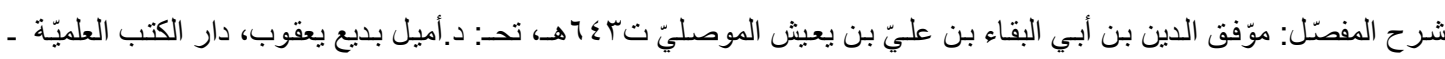

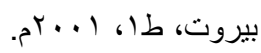
شرح جمل الزجّاجيّ:أبو الحسن علي بن محمّدبن عليّ بن خروف الاشبيليّ تو ـ 7هـ، تد: سلوى محمّد عمر عرب، معهد البحوث

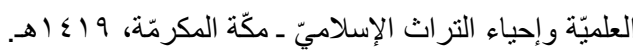

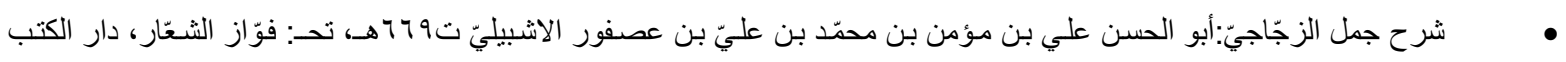
العلميّة - بيروت، طا، 991 ام.

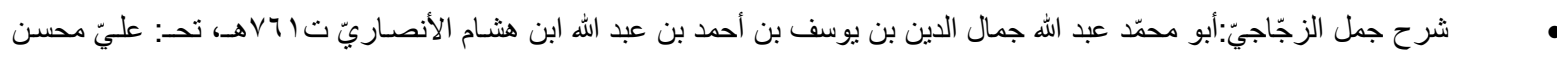
عبسى، عالم الكتب - بيروت، طاح جمل، 910 ام. شو اهد الثعر في كتاب سييويه: د.خالد عبد الكريم جمعة، الدار الثـرقية ـ مصر ، طب، 919 ام.

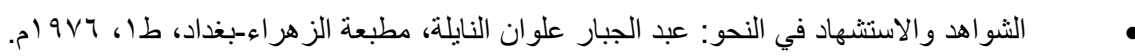

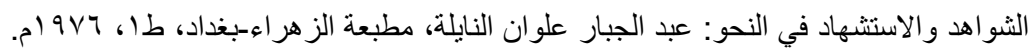




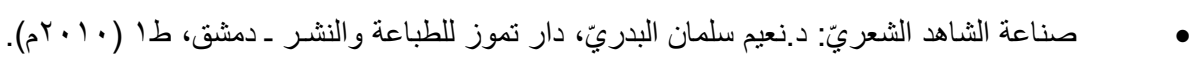

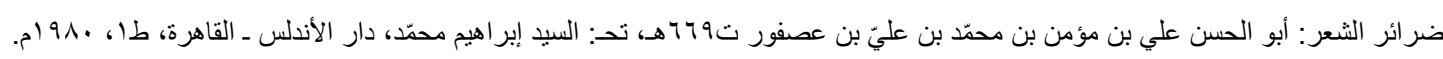

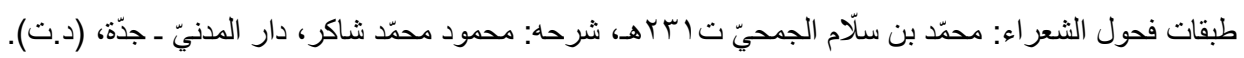

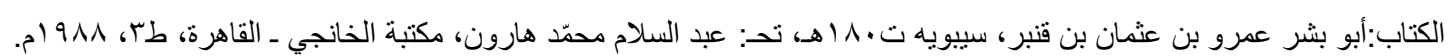

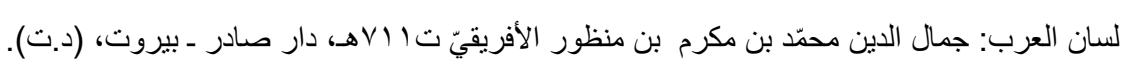

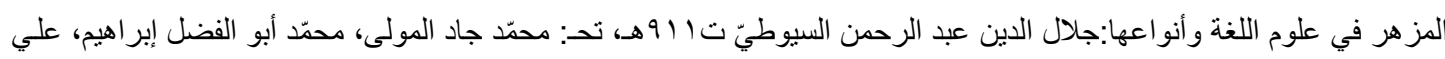

$$
\text { محمّد البجاديّ، المكتبة العصريّة ـ بيروت، (د.ت). }
$$

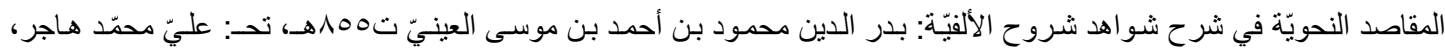

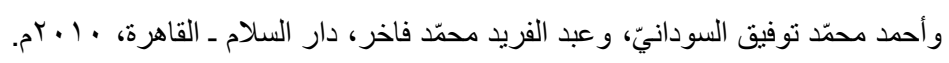

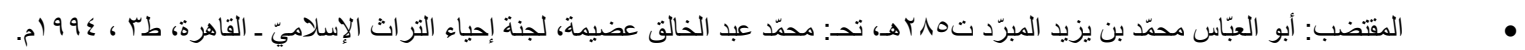

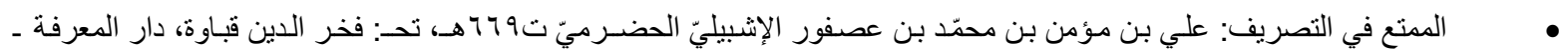

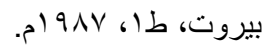

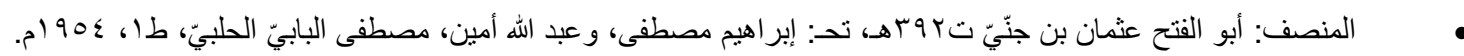

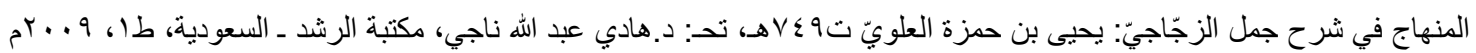

